\title{
Descriptive Study to Assess the Pattern of Usage of Nonprescribed Medication among Adults in Delhi
}

\author{
Tabisha Choudhary ${ }^{1}$, Urmila D Bhardwaj' ${ }^{2}$ Seema Rani ${ }^{3}$ \\ Abstract
}

Introduction: Self-medication or nonprescribed drug use is common in developing countries. Self-medication can be defined as obtaining and consuming drugs without the advice of a physician, either for diagnosis, prescription or surveillance of treatment. Descriptive study was conducted to assess the pattern of usage of nonprescribed medication among adults in Delhi, India.

Objectives: Objectives of the study were to assess the pattern of usage of nonprescribed medication and identify the side effects with usage of nonprescribed medication and establish the relationship of patterns of usage of nonprescribed medication with selected demographic variables, i.e., age, sex, educational status and monthly family income and to develop and disseminate the information booklet on the hazards of using nonprescribed medication.

Methodology: A quantitative approach with descriptive survey design was used to achieve the objectives of the study. Purposive sampling technique was used to select 120 subjects. The study was conducted in Sangam Vihar, New Delhi. The tool used for data collection was a semi-structured interview schedule that was administered to assess the pattern of usage of nonprescribed medications in a selected community of New Delhi. An information booklet on 'Hazards of Usage of Nonprescribed Medications' was developed and disseminated. Data was analyzed using descriptive and inferential statistics.

Result: $86.66 \%$ gave nonprescribed medication to their family members. $36.66 \%$ gave nonprescribed medication to their parents/grandparents. All subjects consumed nonprescribed medication to treat health conditions. There was a significant co-relation between the pattern of usage of non prescribed medication and age, frequency of consuming nonprescribed medication and source of information. There was no significant relationship between age and duration of consuming nonprescribed medication. There was a significant co-relation between educational status and source of information.

Conclusion: An information booklet on hazards of using nonprescribed medication was prepared and disseminated to all subjects. Awareness sessions on the hazards of using nonprescribed medication by the community health nurse or volunteers can help in reduction in the usage of nonprescribed medication in the community.

Keywords: Adult, Hazards, Nonprescribed medication, Self-medication

${ }^{1}$ M. Sc. Nursing Student (Batch 2015 - 2017), ${ }^{2}$ Associate Professor, ${ }^{3}$ Assistant Professor, Rufaida College of Nursing, Jamia Hamdard.

Correspondence: Ms. Seema Rani, Rufaida College of Nursing, Jamia Hamdard.

E-mail Id: seema9rani@yahoo.co.in

Orcid Id: http://orcid.org/0000-0002-3133-448X

How to cite this article: Choudhary T, Bhardwaj UD, Rani S. Descriptive Study to Assess the Pattern of Usage of Nonprescribed Medication among Adults in Delhi. Int J Nurs Midwif Res 2017; 4(3): 42-47.

Digital Object Identifier (DOI): https://doi.org/10.24321/2455.9318.201731

ISSN: $2455-9318$ 


\section{Introduction}

Nonprescribed drugs enable people to relieve many annoying symptoms and to cure some diseases simply, without the cost of seeing a doctor. However, safe use of these drugs requires knowledge, common sense, and responsibility. Self-medication or nonprescribed drug use is common in developing countries. Self-medication can be defined as obtaining and consuming drugs without the advice of a physician, either for diagnosis, prescription or surveillance of treatment. The patients diagnose their own illness and buy a specific drug from the medical shop to treat it. People do self-medication themselves by taking more or less than the recommended dose/frequency of drugs. It has been observed that the people use both prescription or nonprescription drugs for self-medication. Taking self-medication without doctor's prescription can be dangerous as it may lead to dangerous drug interactions and adverse effects. Studies on self-medication patterns and the prevalence of nonprescribed medications in India are lacking. In one study, it was reported that there was an increase in reporting of adverse drug reactions (ADRs) to self-medication. Increasing cost of treatment and poor socioeconomic status in rural areas may increase use of self-medication. ${ }^{1}$

A published study done in Barabanki has indicated that the prevalence of self-medication was more common in males (81\%) as compared to females (19\%) and it was very common in people with 31-45 years of age (44.0\%). Self-medication was more common in illiterate populations (38.7\%). The majority of the respondents were taking Allopathic drugs (69.6\%) followed by Ayurvedic drugs (13.1\%) and Homeopathic drugs (10.7\%). The most common conditions/symptoms for self-medication were fever $(72.6 \%)$, pain $(64.3 \%)$ and respiratory problems (57.1\%), followed by infections, headache and diarrhea. The most commonly used drugs for self-medication were Paracetamol (56.5\%), drugs for gastrointestinal problems (40.5\%), nonsteroidal anti-inflammatory drugs (NSAIDs) (39.9\%), followed by cold remedies, antimicrobials, etc. ${ }^{2}$

In a descriptive study to assess self-medication pattern in Punjab among 300 nuclear families in five different districts, it was found that majority of people go for self-medication without proper knowledge of dose, adverse drug reactions and drug interactions. The study also revealed that the trend of self-medication was higher among the adults as compared to children and old-aged persons who mostly prefered Ayurveda medications. $75 \%$ of them seek advice from the chemists. The common ailments for which they practice self-medication include fever, cough, cold, headache, nutritional loss, etc. Most frequently used drug class was non-steroidal anti-inflammatory drugs. Due to the difficulty in accessing healthcare services, self-medication is often the simplest option for the patients. ${ }^{3}$
A cross-sectional survey was conducted on 200 participants, randomly selected from the coastal regions of south India. Each participant underwent a face-to-face interview with the help of a structured questionnaire. The result reported self-medication use by $71 \%$ of the subjects, which ranged from a frequency of at least one time to a maximum of five times and above. Lack of time (41.5\%), minor illness $(10.5 \%)$ and quick relief $(10 \%)$ were cited as the most common reasons for self-medication use. The majority of the participants (93.5\%) were not aware about the side effects of self-medication. Findings revealed that females and people living in urban areas were more likely to use self-medication than males and people in rural areas. ${ }^{4}$

It has been observed that the consumption of nonprescribed medication is very common in the community, which somehow leads their life into critical illness. Therefore, the investigator felt that there was a well-recognized need to conduct the study to identify the pattern of usage of nonprescribed medication among adults of the community of Delhi, and develop and disseminate an information booklet on the hazards of using nonprescribed medications.

\section{Objective of the Study}

Objectives of the study were to assess the pattern of usage of nonprescribed medication and identify the side effects with usage of nonprescribed medication and establish the relationship of patterns of usage of nonprescribed medication with selected demographic variables, i.e., age, sex, educational status and monthly family income and to develop and disseminate the information booklet on the hazards of using nonprescribed medication.

\section{Material and Methods}

A quantitative approach with descriptive survey design was used to achieve the objectives of the study. Purposive sampling technique was used to select 120 subjects who were adults in the age group of 19-65 years. The study was conducted in Sangam Vihar, New Delhi. The tool used for data collection was a semi-structured interview schedule that was administered to assess the pattern of usage of nonprescribed medications in a selected community of New Delhi. The tool comprised of two sections. Section 1 included background data of adults, (age, sex, educational status, family income) and Section 2 comprised of 52 items pertaining to the pattern of usage of non prescribed medication. The content validity of the tool was established by seven experts from the fields of Nursing, Medicine, Community Health and Surgery. The reliability of the tool was computed by Cronbach's Alpha and was found to be 0.08 . An information booklet on 'Hazard of Usage of Nonprescribed Medications' was developed in Hindi. The content of the information booklet included high risk takers of nonprescribed medications, common harmful effects of the same and measures to avoid the harmful effects. 
Ethical permission was sought from Institutional Review Board (IRB), Jamia Hamdard. Formal permission was taken from the councillors of Tughlakabad and Sangam Vihar. Informed consent was taken from the subjects and the confidentiality of their responses was assured. The time taken to conduct the interview was 45 minutes form each subject. Information booklet was distributed following the interview. Data was analyzed using descriptive and inferential statistics.

\section{Results}

\section{Findings related to the Background Profile}

Majority of the subjects 42 (35\%) were in the age group of 19-30 years, 37 (30.83\%) were in the age group of 31-40 years, $23(19.17 \%)$ were in the age group of $41-50$ years and $18(15 \%)$ were in the age group of $51-65$ years. $53.33 \%$ subjects were female and $46.67 \%$ were male. $81.67 \%$ subjects belonged to the Hindu religion, $17.5 \%$ belonged to Muslim religion and $1.83 \%$ were Christians. As regards monthly family income, $38.33 \%$ subjects had Rs. 5001/$-10,000 /-, 38.33 \%$ subject had Rs. 10,001/--20,000/-, $15 \%$ subjects had above $20,000 /-$ and $8.33 \%$ subjects had below Rs 5,000/-.
$86.66 \%$ subjects had given the nonprescribed medicines to their family members. $36.66 \%$ subjects gave the nonprescribed medicine to parents or grandparents, $34.16 \%$ gave to their children, $28.33 \%$ to the spouse and $17.5 \%$ consumed themselves.

\section{Findings related to the Assessment of Pattern of Usage of Nonprescribed Medication}

Out of 120 study subjects, $42.5 \%$ subjects had been taking nonprescribed medicines for less than one year, $34.16 \%$ for more than 5 years, $12.5 \%$ subjects had been taking for 1 year to 3 years and $10.83 \%$ subjects had been taking the nonprescribed medicines for 3 years to 5 years.

78.33\% subjects consumed the nonprescribed medicines occasionally, $9.16 \%$ on daily basis, $5.83 \%$ subjects on weekly basis and $5 \%$ subjects on monthly basis.

$47.5 \%$ subjects got the information regarding the medicines from the pharmacist, $35.83 \%$ subjects from relatives/ friends, $15.83 \%$ from old prescription of doctors and $12.5 \%$ subjects from TV, radio, mass media, magazines, etc., and only $7.5 \%$ subjects got information from other sources (Fig. 1).

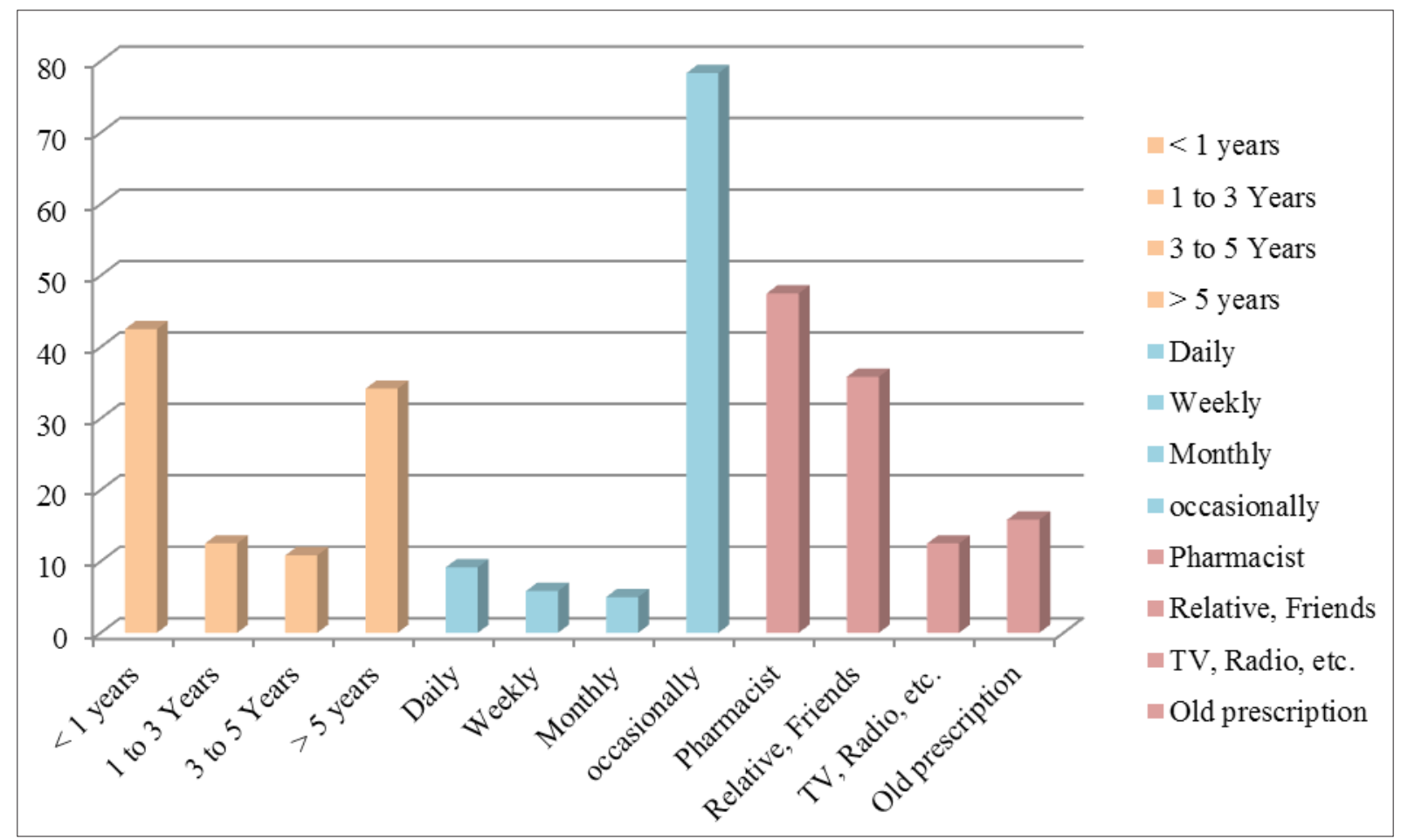

Figure 1.Component Bar Diagram Showing the Pattern of Using Nonprescribed Medicine (Duration of consumption of medicine, Frequency of taking medicine and Source of Information about the Nonprescribed Medicine) 
Findings related to the Type of Nonprescribed Medication Consumed by Adults and Their Side Effects (Tables 1 and 2)

Table 1.Frequency and Percentage of Adults as per the Intake of Medications, Problems and Reasons for Taking Nonprescribed Medication

\begin{tabular}{|c|c|c|}
\hline Sample Characteristics & Frequency (f) & Percentage (\%) \\
\hline \multicolumn{3}{|l|}{ Type of Medication* } \\
\hline Ayurvedic & 9 & 7.5 \\
\hline Unani & 3 & 2.5 \\
\hline Allopathy & 99 & 82.5 \\
\hline Homeopathy & 9 & 7.5 \\
\hline \multicolumn{3}{|l|}{ Problems* } \\
\hline Pain & 106 & 88.33 \\
\hline Fever & 83 & 69.17 \\
\hline Stomach Ache & 41 & 34.17 \\
\hline Vomiting & 18 & 15 \\
\hline Diarrhea & 16 & 13.33 \\
\hline Cold and cough & 67 & 55.83 \\
\hline High blood pressure & 06 & 5 \\
\hline Diabetes mellitus & 03 & 2.5 \\
\hline Acidity & 41 & 34.17 \\
\hline Anxiety & 03 & 2.5 \\
\hline Allergic reactions & 15 & 12.5 \\
\hline Sleep problems & 04 & 3.33 \\
\hline Infection & 18 & 15 \\
\hline \multicolumn{3}{|l|}{ Reason* } \\
\hline Can't afford the fee of private doctors & 22 & 18.33 \\
\hline Long distance of health facilities from home & 26 & 21.67 \\
\hline Want to save time and money & 87 & 72.5 \\
\hline Any other & 03 & 2.5 \\
\hline
\end{tabular}

*The item has multiple options to respond

Table 2.Frequency and Percentage of Adults as per the Type and Side Effects of Nonprescribed Medication

\begin{tabular}{|c|c|c|c|c|c|}
\hline S. No. & Type of Drug* & \multicolumn{2}{|c|}{ Users } & \multicolumn{2}{c|}{ Side Effects } \\
\cline { 3 - 6 } & & Number of Subjects (n) & Percentage (\%) & Number of Subjects ( $\mathrm{n}$ ) & Percentage (\%) \\
\hline 1. & Analgesics & 106 & 88.33 & 15 & 14.15 \\
\hline 2. & Anti-pyretics & 83 & 69.16 & 9 & 10.84 \\
\hline 3. & Anti-spasmodic & 41 & 34.16 & 4 & 9.75 \\
\hline 4. & Anti-tussive & 67 & 55.83 & 5 & 7.46 \\
\hline 5. & Antacid & 41 & 34.16 & 4 & 9.75 \\
\hline 6. & Antibiotics & 18 & 15 & 5 & 27.77 \\
\hline
\end{tabular}

*The item has multiple options to respond

Finding related to Association between the Pattern of Usage of Nonprescribed Medication with Selected Demographic Variables

The findings showed that there was no significant association between the duration of consuming nonprescribed medication and age of the adults, but there was a significant association between the frequency of consuming nonprescribed medication and age of the adults and there was also a significant association between the source of information about the nonprescribed medication and age of the adults. Fisher's exact value test showing the association between age and pattern of usage of nonprescribed medication is represented in Table 3.

The finding show that there is no significant association between the duration of consuming nonprescribed medication and educational status of the adults and also there is no significant association between the frequency of consuming nonprescribed medication and educational status of the adults. But there is a significant association between the source of information about the nonprescribed medication and educational status of the adults. Fisher's exact value test showing the association between educational status and pattern of usage of nonprescribed medication is shown in Table 4. 
Table 3.Fisher's exact test showing the association between age and pattern of usage of nonprescribed medication

\begin{tabular}{|c|c|c|c|c|c|c|}
\hline & \multicolumn{4}{|c|}{ Age ( in Years) } & \multirow[t]{2}{*}{ Fisher's Exact Value } & \multirow[t]{2}{*}{$p$-Value } \\
\hline & $19-30$ & $31-40$ & $41-50$ & $51-65$ & & \\
\hline \multicolumn{7}{|l|}{ Duration ( in Years) } \\
\hline$<1$ & 19 & 13 & 12 & 7 & \multirow{4}{*}{10.4693} & \multirow{4}{*}{.313846} \\
\hline $1-3$ & 7 & 7 & 0 & 1 & & \\
\hline $3-5$ & 3 & 6 & 3 & 1 & & \\
\hline$>5$ & 12 & 11 & 9 & 9 & & \\
\hline \multicolumn{7}{|l|}{ Frequency } \\
\hline Daily & 3 & 1 & 5 & 2 & \multirow{4}{*}{17.9317} & \multirow{4}{*}{$.035974^{*}$} \\
\hline Weekly & 3 & 1 & 3 & 1 & & \\
\hline Monthly & 2 & 1 & 2 & 2 & & \\
\hline Occasionally & 33 & 36 & 12 & 13 & & \\
\hline \multicolumn{7}{|c|}{ *Source of information } \\
\hline Pharmacist & 13 & 17 & 15 & 12 & \multirow{4}{*}{17.5555} & \multirow{4}{*}{$.040696^{*}$} \\
\hline Relatives, friends & 19 & 10 & 8 & 6 & & \\
\hline TV, radio, etc. & 7 & 4 & 1 & 3 & & \\
\hline Old prescription & 6 & 11 & 0 & 2 & & \\
\hline
\end{tabular}

Table 4.Fisher's Exact Test Showing the Association between Educational Status and Pattern of Usage of Nonprescribed Medication

\begin{tabular}{|c|c|c|c|c|c|c|c|}
\hline & \multicolumn{5}{|c|}{ Educational Status } & \multirow[t]{2}{*}{ Fisher's Exact Value } & \multirow[t]{2}{*}{$p$-Value } \\
\hline & Illiterate & Primary & Secondary & Graduate & Postgraduate & & \\
\hline \multicolumn{8}{|l|}{ Duration ( in Years) } \\
\hline$<1$ & 8 & 11 & 22 & 8 & 2 & \multirow{4}{*}{9.1407} & \multirow{4}{*}{.690868} \\
\hline $1-3$ & 1 & 4 & 6 & 3 & 1 & & \\
\hline $3-5$ & 3 & 2 & 6 & 2 & 0 & & \\
\hline$>5$ & 8 & 8 & 12 & 13 & 0 & & \\
\hline \multicolumn{8}{|l|}{ Frequency } \\
\hline Daily & 2 & 2 & 6 & 1 & 0 & \multirow[t]{4}{*}{4.5026} & \multirow[t]{4}{*}{.972568} \\
\hline Weekly & 2 & 1 & 4 & 1 & 0 & & \\
\hline Monthly & 1 & 1 & 4 & 1 & 0 & & \\
\hline Occasionally & 14 & 21 & 33 & 23 & 3 & & \\
\hline \multicolumn{8}{|c|}{ *Source of information } \\
\hline Pharmacist & 11 & 16 & 24 & 3 & 1 & \multirow[t]{4}{*}{36.7092} & \multirow[t]{4}{*}{$.000249^{*}$} \\
\hline Relatives, friends & 8 & 7 & 16 & 12 & 0 & & \\
\hline TV, radio, etc. & 1 & 2 & 6 & 6 & 0 & & \\
\hline Old prescription & 1 & 4 & 2 & 9 & 3 & & \\
\hline
\end{tabular}

*The item has multiple options to respond; *Significant at 0.05 level 


\section{Discussion}

The findings of the current study are in line with the study conducted by Yogendra et al. in Pune, India, as both the studies showed that there was no association between the pattern of usage of nonprescribed medication and the gender of the users. Majority of the samples following in low socioeconomic strata, i.e., with family income $<$ Rs. 10,000 were found to be consuming nonprescribed medication. Also in both the studies, main reasons for consuming nonprescribed medicines were revealed as in-affordability of the private healthcare facilities and long waiting time at government health setup. ${ }^{1}$

The findings of the present study are similar to a study conducted by Shveta et al. in Punjab as present study showed that majority of subjects are taking analgesics, antipyretics, anti-spasmodic, anti-tussive, antacids and antibiotics, many of them having side effects of taking nonprescribed medication among 300 nuclear families in five districts, and it is found in that study that majority of people go for nonprescribed medication, i.e., analgesics, antipyretics, anti-tussive, antacids and antibiotics, 20\% people experienced the side effects of non-prescribed medication at any point of time. ${ }^{3}$

A study conducted by Reetesh et al. in Bhopal, India, with a sample of 166 participants revealed that the factors which lead to nonprescribed medication were quick relief (58.6\%), lack of time (23.3\%) and high consultation fee (18.1\%), which were similar to the present study. ${ }^{5}$

\section{Conclusion}

Findings showed that subjects had experienced harmful reaction from using of nonprescribed medications and found a significant co-relation between frequency, source of information, age, and education status. As far as co-relation between duration and age, sex, education status, and family monthly income concerns, the study found no co-relation. On the basis of the findings of the study, some implications were made, a booklet was developed on hazards of using nonprescribed medication and disseminated to all subjects and awareness sessions on the hazards of using nonprescribed medication by the community health nurse or volunteers, which can help in reduction of usage of nonprescribed medication.

\section{Conflict of interest: None}

\section{References}

1. Keche $Y$ et al. Self medication pattern in rural areas in Pune, India. International Journal of Medicine and Public Health Oct-Dec 2012; 2(4).

2. Keshri SS et al. Prevalence and pattern of self medication practices in rural area of Barabanki. Indian Journal of Clinical Practice Dec 2014; 25(7).

3. Shveta S, Jagmohan $S$. A study of self medication pattern in Punjab. Indian Journal of Pharmacy Practice [online] 2011 [cited on 2012 Jul 15]; 4(2): 43-46. Available from: http://www.ijopp.org/apr-jun-2011/43-46.pdf//.

4. Balmurugan $E$, Ganesh K. Prevalence and patterns of self-medication use in coastal regions of South India. BJMP 2011; 4(3): 428. Available from: http//www.bjmp. org.content/prevelance-and-pattern-self medicationuse-coastal-regions-south-India.

5. Reetesh M, Papiya B, Sonam J. A study of self medication among the people of Bhopal region Madhya Pradesh, India. International Research Journal of Pharmacy [online] 2011 [cited on $2012 \mathrm{Jul}$ 4]; 2(12); 163-65. Available from: http://www.irjponline.com/admin/ php/uploads/745-pdf.

Date of Submission: 2017-08-14

Date of Acceptance: 2017-10-04 